\title{
Selection Of The Best Employees Using Analytical Hierarchy Process at PT. Gotrans Logsitics International Semarang Branch
}

\author{
Bachtiar Dwi Hari Putranto ${ }^{1}$, Dedy Kurniadi ${ }^{2}$, Asih Widiharini ${ }^{3}$ \\ 1 Universitas Islam Sultan Agung / Teknik Informatika \\ 2 Universitas Islam Sultan Agung / Teknik Informatika \\ 3 Universitas Islam Sultan Agung / Teknik Informatika
}

\begin{abstract}
One form of appreciation that a company gives to employees is the selection of one or several employees to be the best employees, usually companies implement this program for the benefit of their respective companies. This program is also carried out by PT. Gotrans Logistics International Semarang branch to motivate the development of the quality of human resources to compete in a healthy manner which indirectly also has a good impact on the company. This best employee selection program will take a long time and the results are inaccurate if not assisted by a decision support system, therefore a decision support system is needed to get the expected results. Selection will be carried out by determining the weight of the desired criteria and then ranking the employees. With the creation of a decision support system using the Analytical Hierarchy Process (AHP) method, it can provide a solution in performing calculations and minimizing the time used in the selection.
\end{abstract}

Keywords: : Decision Support System, Best Employee Selection, Analytical Hierarchy Process.

correspondingemail : bahtiardwihp@std.unissula.ac.id

This is an open access article under the CC BY license

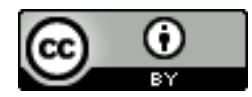

\section{INTRODUCTION}

Pada dasarnya, beroperasinya sebuah perusahaan tidak lepas dari peran karyawan yang berpartisipasi memberikan jasa dan tenaga kerjanya. Hubungan antara Perusahaan dan Karyawan adalah dua hal yang tidak dapat dipisahkan karena menguntungkan satu sama lain, perusahaaan memberikan balas jasa berupa gaji yang besarannya telah disepakati oleh kedua belah pihak. [1] PT. Gotrans Logistics International cabang Semarang adalah perusahaan yang bergerak di bidang pengadaan dan pengiriman barang ke beberapa penjuru cabang yang ada di Indonesia, bagi PT. Gotrans Logistics International cabang Semarang karyawan adalah aset perusahaan yang paling berharga karena menjadi ujung tombak perusahaan mengingat perusahaan ini bergerak di bidang pengadaan dan pengiriman barang, peran karyawan sangat berpengaruh terhadap kualitas pelayanan. Untuk mempertahankan dan meningkatkan kualitas sumber daya manusia ini pemilihan karyawan terbaik dilakukan oleh PT. Gotrans Logistics International cabang Semarang dengan memberikan apresiasi kepada karyawan yang terpilih.

Dalam Penyeleksian yang dilakukan, PT. Gotrans Logistics International cabang Semarang mendapatkan masalah pada lamanya waktu yang dibutuhkan untuk menyeleksi 24 karyawan. Berdasarkan permasalahan yang dimiliki PT. Gotrans Logistics International cabang Semarang maka dibutuhkan sebuah sistem pendukung keputusan pemilihan karyawan terbaik berbasis web dengan metode Analytical Hierarchy Process menggunakan bahasa pemograman PHP dan MySQL sebagai basis datanya agar dapat menjadi alternatif dalam pemilihan karyawan terbaik di PT. Gotrans Logistics International cabang Semarang. 
JAST : Journal of Applied Science and Technology

Volume. 1 Number. 2, July 2021

ISSN : 2775-4022

http://jurnal.unissula.ac.id/index.php/JAST

\section{LITERATURE REVIEW}

\subsection{Tinjauan Pustaka}

Terdapat beberapa penilitan terkait penelitian sebelumnya, yang digunakan penulis sebagai studi literatur, yang pertama adalah penelitian Sistem Pendukung Keputusan Penerimaan Pegawai pada Universitas Ekasakti Menggunakan Metode AHP yang dilakukan oleh Zainul Efendy dan Azizel Wanjas Saputra Genda pada tahun 2018. dengan Model penerapan logika dinamis yang diterapkan dalam AHP memilki keuntungan dimana proses penyelesaian memberikan hasil yang sangat fleksibel dalam memecahkan kasus seleksi penerimaan pegawai dengan hasil yang akurat.[2]

Penelitian berikutnya dilakukan oleh Munthe dkk pada tahun 2018 berjudul Sistem Pendukung Keputusan menentukan karyawan Perusahaan menggunakan metode AHP. menurutnya kualitas kinerja setiap karyawan dalam sebuah perusahaan menjadi penentu berhasilnya tujuan perusahaan. Oleh sebab itu, perlu diadakan penilaian kinerja agar karyawan dapat bekerja secara kompetitif dan profesional. Dengan menggunakan metode AHP ini, hasil dari pemilihan karyawan akan lebih akurat dan cepat. Hasil akhir menunjukan bahwa metode AHP berhasil diterapkan.[3]

Penelitian selanjutnya dilakukan oleh Ibrahim dan Karis di tahun 2017 yang berjudul Sistem Pendukung Keputusan Pemilihan Karyawan Terbaik di PT.Virama Karya Cabang Semarang yang dilatarbelakangi belum adanya standarisasi penilaian sumber daya manusia. Hasil akhir menunjukan bahwa AHP berhasil diterapkan dalam membantu proses pemilihan karyawan.[4]

Penelitian lainnya dilakukan oleh Wijaya pada tahun 2019 dengan judul Sistem Pendukung Keputusan Pemilihan Karyawan Berprestasi. Menurut penelitian yang dilakukan Wijaya, perusahaan harus memilih karyawan yang berprestasi dengan kriteria-kriteria yang telah ditetapkan oleh perusahaan tersebut, maka diperlukan suatu sistem pendukung keputusan untuk pemilihan karyawan berprestasi menggunakan metode AHP agar pemilihan karyawan berprestasi dapat selesai dengan akurat dan cepat. Hasil akhir menunjukan bahwa metode AHP berhasil diterapkan.[5]

\subsection{Landasan Teori}

\subsubsection{Sistem Pendukung Keputusan}

Sistem Pendukung Keputusan merupakan suatu sistem informasi yang didalamnya meliputi informasi, pemodelan serta manipulasi data. Ketika seseorang menjumpai situasi yang semi terstruktural dan tidak terstruktur, seseorang tersebut tidak tahu secara pasti tentang bagaimana keputusan seharusnya dibuat. Sistem Pendukung Keputusan biasanya dibangun bertujuan untuk mendapatkan serta mendukung solusi atas suatu permasalahan atau untuk mengevaluasi suatu peluang. Sistem Pendukung Keputusan seperti ini disebut sebagai Aplikasi Sistem Pendukung Keputusan yang menggunakan CBIS (Computer Based Information System) yang interaktif, fleksibel, diadaptasi, dan dapat dikembangkan untuk menyelesaikan manajemen spesifik yang tidak terstruktur.[6]

\subsubsection{Karyawan}

Karyawan adalah seseorang yang menggunakan tenaganya untuk bekerja kepada pengusaha yang sebelumnya telah melakukan kesepakatan dengan imbalan berupa gaji dan pengusaha menerima hasil karyanya itu sesuai dengan profesi atau pekerjaan atas dasar keahlian sebagai mata pencahariannya. Sesuai dengan UndangUndang No. 14 Tahun 1969 mengenai pokok tenaga kerja karyawan adalah setiap orangnya mampu melakukan pekerjaan untuk menghasilkan jasa atau barang untuk memenuhi kebutuhan masyarakat.[5]

\section{RESEARCH METHOD}

\subsection{Metode Penelitian}

Metode yang penulis gunakan adalah waterfall, secara garis besar memiliki langkah-langkah sebagai berikut : Analisa, Desain, Penulisan Kode Program, Pengujian Program dan Penerapan Program dan Pemeliharaan [7]

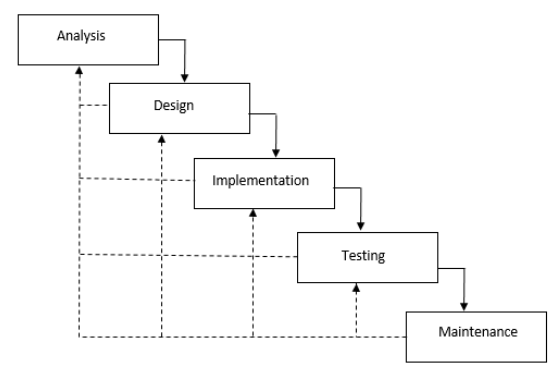

Gambar 1. Waterfall 
JAST : Journal of Applied Science and Technology

Volume. 1 Number. 2, July 2021

ISSN : 2775-4022

http://jurnal.unissula.ac.id/index.php/JAST

\subsection{Analytical Hierarchy Process}

Analytical Hierarchy Process merupakan metodologi yang dikembangkan oleh Dr. Thomas L. Saaty yang digunakan untuk memecahkan masalah yang tidak terstruktur, data statistik sangat minim atau tidak ada sama sekali yang hanya bersifat kualitatif didasari oleh sebuah presepsi lalu mengubahnya dalam bentuk hierarki dan digambarkan secara grafis sehingga pihak-pihak yang melihat dapat memahami dengan mudah dan jelas agar dapat melakukan pengambilan keputusan dengan lebih baik. Analytical Hierarchy Process dapat menjadi solusi permasalahan di sebuah Perusahaan seperti penentuan karyawan terbaik.[8]

\subsection{Tahapan Perhitungan Metode AHP}

Berikut adala htahapan-tahapan perhitungan AHP dari meyusun hirarki, perbadingan berpasangan, normalisasi, menghitung eigen vector, mengitung $\lambda$ max, menghitung konsistensi indeks, menghitung rasio kosistensi hingga menghitung hasil [9]

\section{a. Menyusun Hirarki}

Tahapan yang dilakukan meliputi Menyusun hirarki dari permasalahan yang dijumpai dengan menampilkan unsur-unsur permasalahan dan data diterapkan pada permasalahan yang dihadapi di PT. Gotrans Logistics International cabang Semarang.

\section{b. Perbandingan Berpasangan}

Tabel 1 adalah skala perbandingan berpasangan untuk menentukan prioritas elemen kriteria dan alternatif. Terdapat dua tahap penelitian atau perbandingan antara elemen, yaitu penilaian elemen kriteria dan penilaian elemen alternatif. Penilaian elemen kriteria bertujuan untuk menentukan bobot untuk masingmasing kriteria. Sedangkan penilaian elemen alternatif bertujuan untuk mengetahui bobot suatu alternatif. Jadi penilain ini dimaksudkan untuk melihat seberapa penting suatu pilihan dilihat dari kriteria tersebut.

Tabel 1 Skala Penilaian Perbandingan Pasangan

\begin{tabular}{|l|l|}
\hline Intensitas Kepentingan & Keterangan \\
\hline 1 & Kedua elemen sama pentingnya \\
\hline 3 & Elemen yang satu sedikit lebih penting daripada elemen lainnya \\
\hline 5 & Elemen yang satu lebih penting daripada elemen lainnya \\
\hline 7 & Satu elemen jelas lebih mutlak penting daripada elemen lainnya \\
\hline 9 & Satu elemen mutlak penting daripada elemen lainnya \\
\hline Kebalikan & Nilai-nilai anara dua nilai pertimbangan yang berdekatan \\
\hline
\end{tabular}

\section{c. Melakukan normalisasi}

Yaitu membagi tiap kolom pada tiap baris dengan jumlah total nilai dari setiap baris

\section{d. Menghitung nilai Eigen Vektor}

Dengan menjumlahkan semua kolom dari tiap baris kemudian dibagi jumlah $\mathrm{N}$ atau elemen

\section{e. Menghitung $\lambda$ Maks}

Untuk mencari nilai max adalah dengan rumus sebagai berikut

$$
\lambda \operatorname{maks}=\frac{\text { Penjumlahan prioritas dengan jumlah per baris }}{n}
$$

\section{f. Menghitung nilai Consistency Index (CI)}

Untuk mencari nilai CI adalah sebagai berikut 


$$
C I=\frac{\lambda m a k s-n}{n-1}
$$

\section{g. Menentukan nilai RI}

Tabel 2 adalah tabel nilai RI yang sesuai dengan jumlah banyaknya krieria

Tabel 2. Nilai Random RI

\begin{tabular}{|c|c|c|c|c|c|c|c|c|c|c|c|c|}
\hline $\mathrm{N}$ & 1 & 2 & 3 & 4 & 5 & 6 & 7 & 8 & 9 & 10 & 11 & $\cdots$ \\
\hline R.I. & 0.00 & 0.00 & 0.58 & 0.90 & 1.12 & 1.24 & 1.32 & 1.41 & 1.45 & 1.49 & 1.51 & $\cdots$ \\
& & & & & & & & & & & & \\
\hline
\end{tabular}

h. Mencari nilai Consistency Ratio (CR)

Nilai CR harus kurang dari sama dengan $<=0,1$ atau $10 \%$

$$
C R=\frac{C I}{R I}
$$

\section{i. Menghitung Hasil}

Berdasarkan perhitungan yang telah dilalui, data karyawan akan muncul sesuai urutan penilaian dari yang tertinggi sampai nilai terendah

\subsection{Use Case Diagram}

Perancangan proses sistem yang akan dikembangkan menggunakan UML Gambar 1 adalah Use Case Diagram yang merupakan salah satu jenis diagram pada UML yang menggambarkan interaksi antara sistem dan aktor [10]

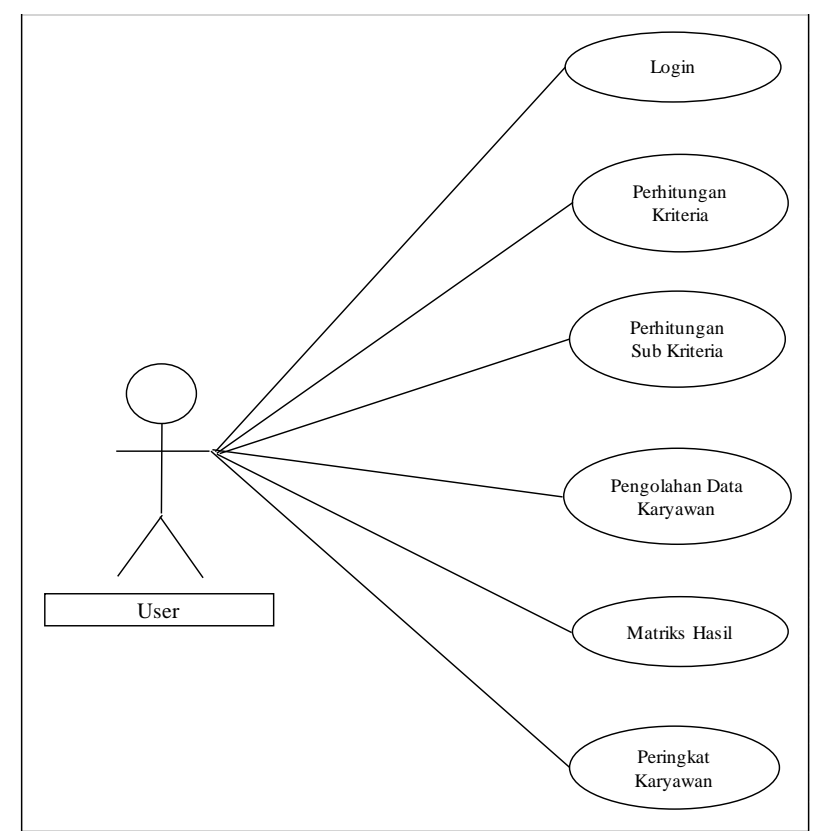

Gambar 2. Use Case Diagram

\subsection{Sequence Diagram}

Pada gambar 3.5 merupakan suatu tahapan yang terjadi pada proses seleksi pemilihan karyawan terbaik di PT. Gotrans Logistics International cabang Semarang yang dijalankan meliputi halaman awal sistem, penginputan data karyawan, penginputan nilai kriteria dan sub kriteria, dan hasil perankingan penentuan karyawan terbaik yang terpilih sesuai seleksi perhitungan 
JAST : Journal of Applied Science and Technology

Volume. 1 Number. 2, July 2021

ISSN : 2775-4022

http://jurnal.unissula.ac.id/index.php/JAST

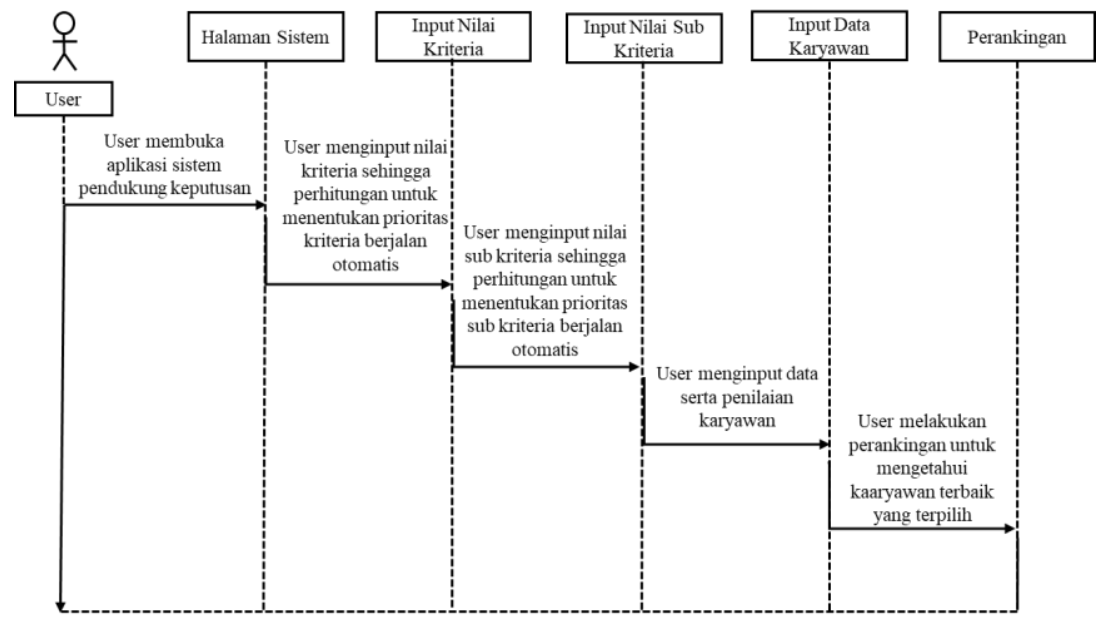

Gambar 3. Sequence Diagram

\subsection{Activity Diagram}

Gambar 3 adalah Activity Diagram yang memperlihatkan fungsi-fungsi dari sebuah sistem yang dibangun dari awal sampai akhir. Diagram ini menunjukan langkah-langkah dalam proses kerja sistem yang kita buat

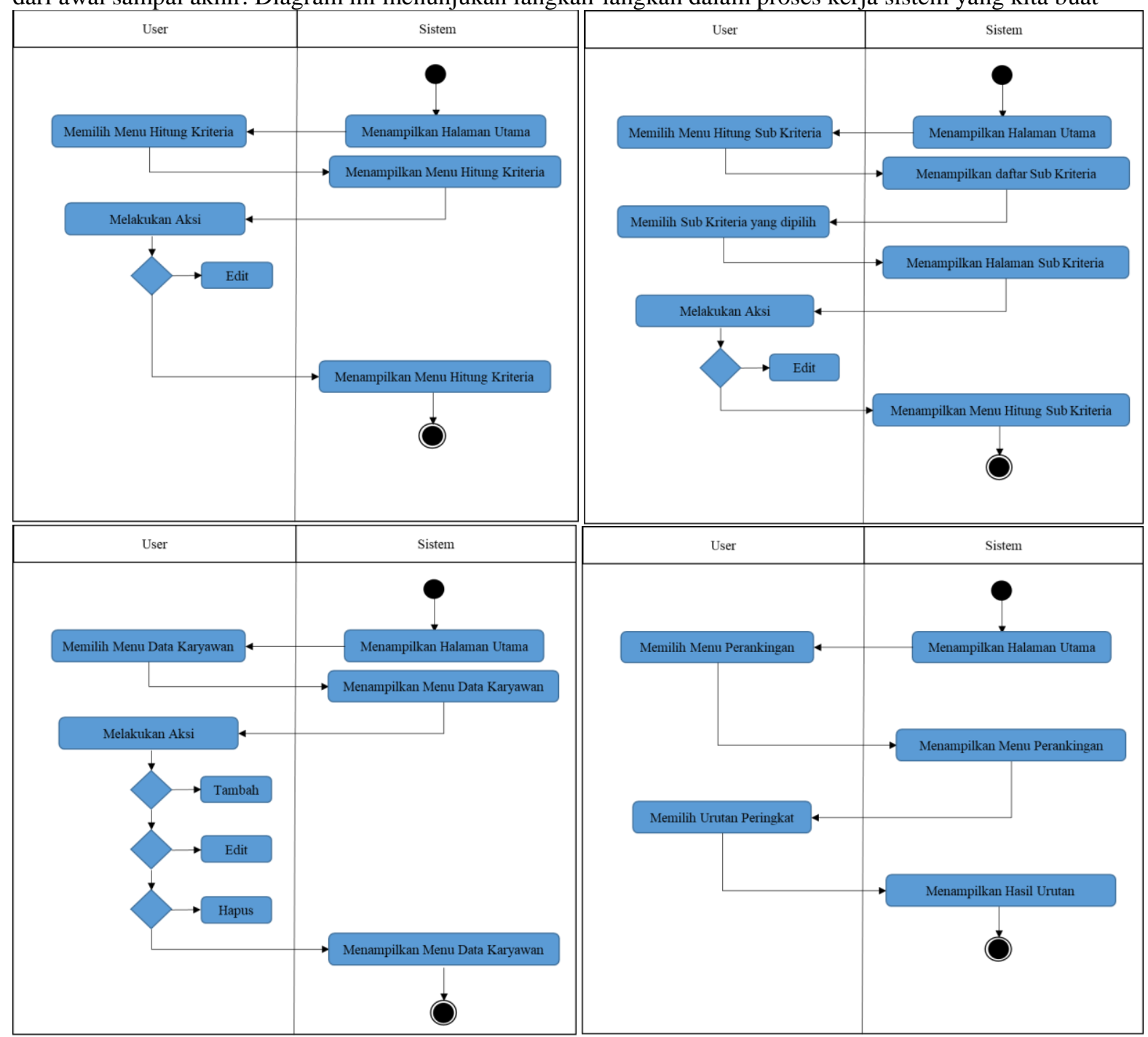

Gambar 4. Activity Diagram 
JAST : Journal of Applied Science and Technology

Volume. 1 Number. 2, July 2021

ISSN : 2775-4022

http://jurnal.unissula.ac.id/index.php/JAST

\section{RESULT AND ANALYSIST}

\subsection{Halaman Beranda}

Gambar 5 adalah halaman Beranda, yang tampil setelah user berhasil login, terdapat fitur tambah data karyawan, edit, dan menghapus

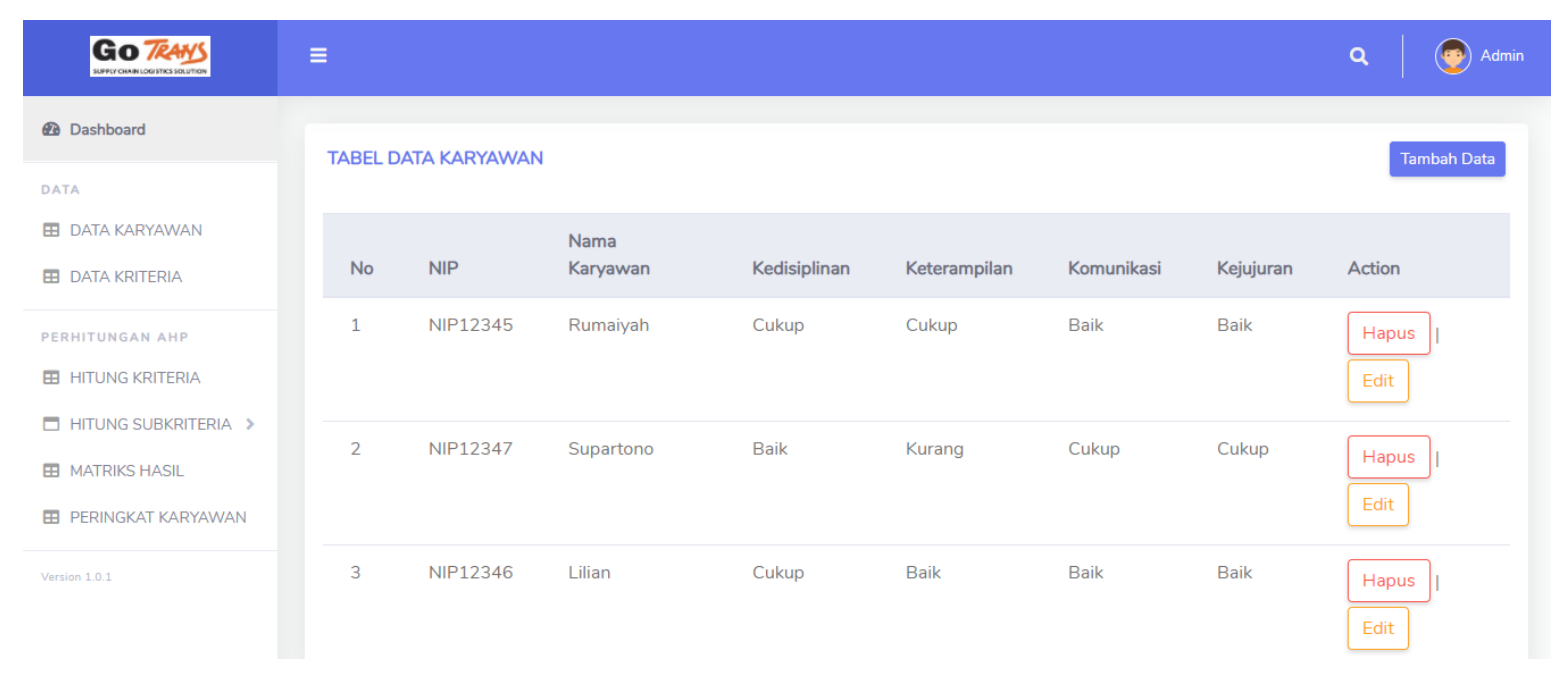

Gambar 5. Halaman Beranda

\subsection{Halaman Tambah Data Karyawan}

Gambar 6 adalah halaman yang tampil setelah menekan fitur tambah data pada halaman data karyawan, yang meliputi penginputan nama, nomor induk karyawan, dan penilaian dari masing-masing kriteria.

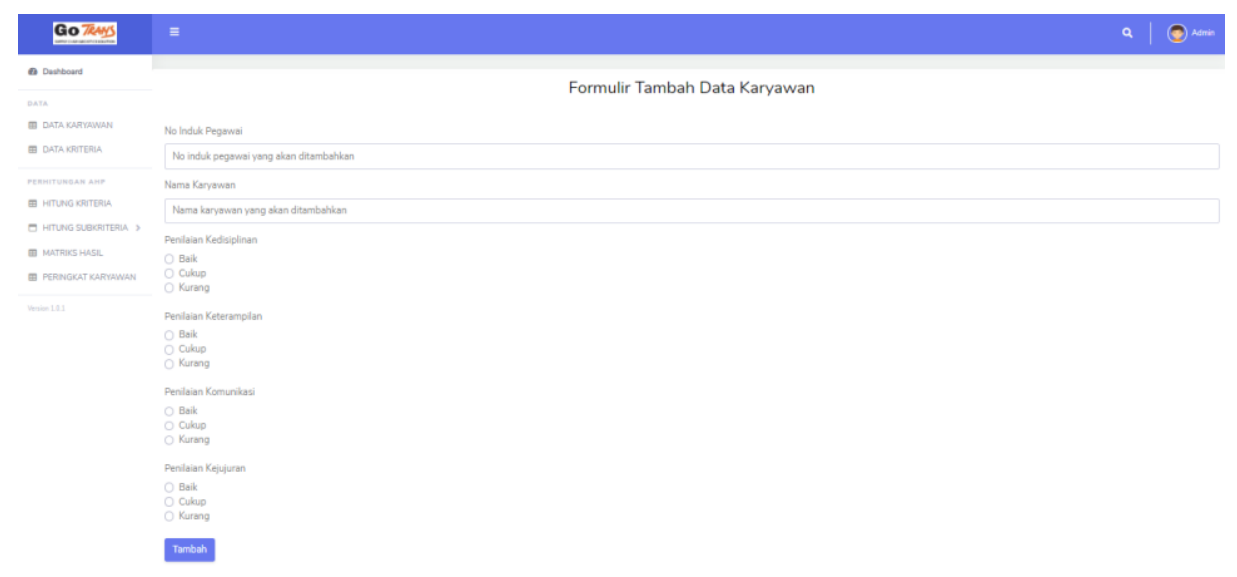

Gambar 6. Halaman Tambah Data Karyawan

\subsection{Halaman Perhitungan}

Gambar 7 adalah halaman yang menampilkan hasil perhitungan untuk menemukan nilai prioritas kriteria, sub kriteria hingga penentuan konsistensi logis 
JAST : Journal of Applied Science and Technology

Volume. 1 Number. 2, July 2021

ISSN : 2775-4022

http://jurnal.unissula.ac.id/index.php/JAST

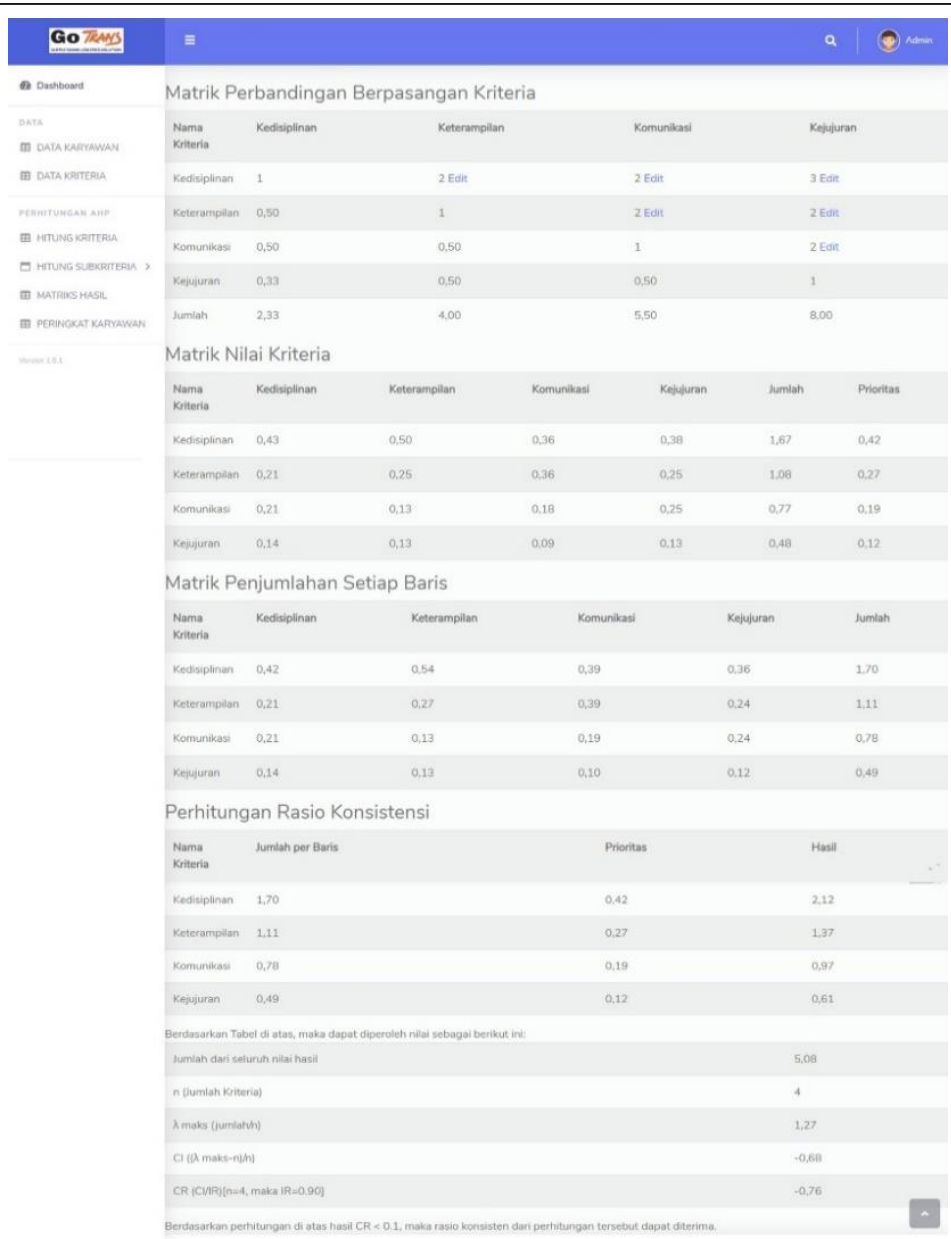

\subsection{Halaman Matriks Hasil}

Gambar 7. Halaman Perhitungan

Gambar 8 adalah halaman matriks hasil yang berisi nilai-nilai yang terpilih menjadi prioritas pada kriteria dan sub kriteria setelah melalui perhitungan sistem

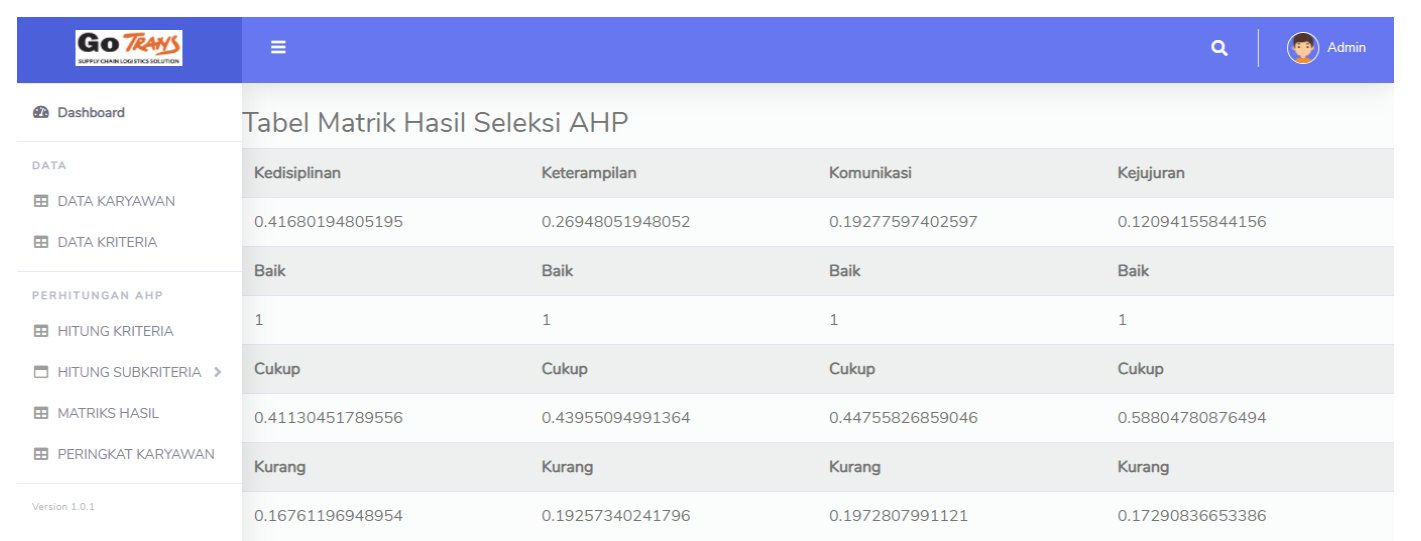

Gambar 8. Halaman Matriks Hasil

\subsection{Halaman Perankingan}

Gambar 9 adalah halaman perankingan yang memiliki fitur untuk mengurutkan peringkat karyawan sesuai dengan penilaian atau data yang dimasukkan dan diseleksi melalui perhitungan sistem 


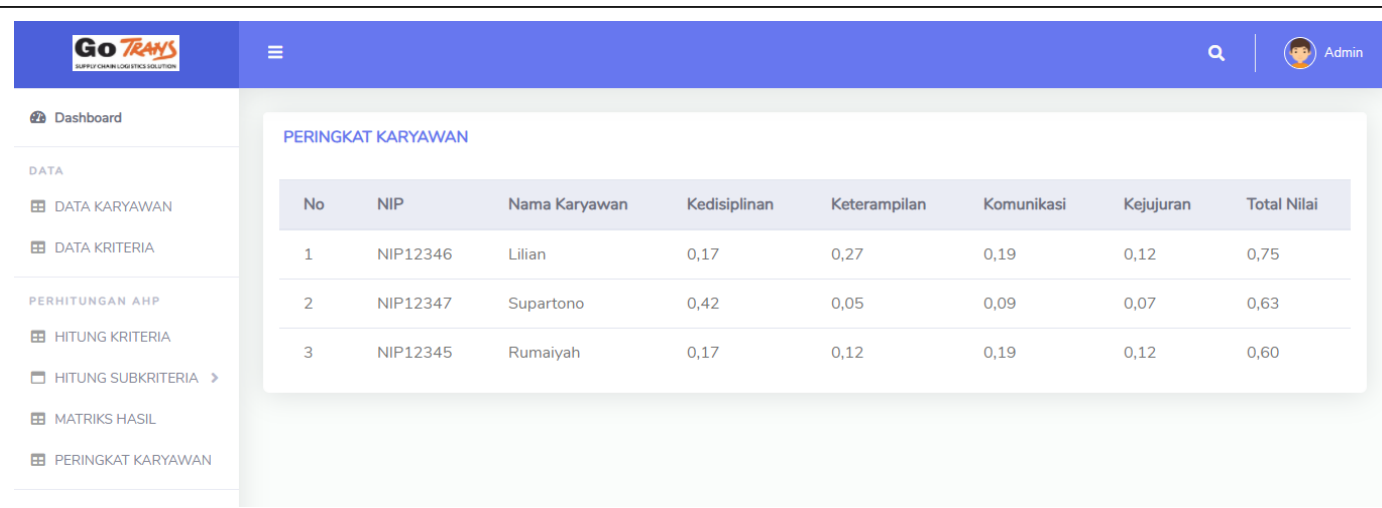

Gambar 9. Halaman Perankingan

\section{CONCLUSION}

Berdasarkan hasil penilitan tersebut, maka dapat disimpulkan Sistem Pendukung Keputusan dengan metode Analytical Hierarchy Process ini dapat berjalan dengan baik sesuai dengan metode yang digunakan serta menjadi alternaatif yang diharapkan dalam perankingan karyawan terbaik di PT. Gotrans Logistics International cabang Semarang

\section{DAFTAR PUSTAKA}

[1] K. Safitri and F. T. Waruwu, "Pemilihan Karyawan Berprestasi Menggunakan Metode AHP ( Studi Kasus : PT . Capella Dinamik Nusantara Takengon )," vol. 1, no. 1, pp. 17-21, 2017.

[2] Zainul Efendy dan Azizel Wanjas Saputra Genda, "Indonesian Journal of Computer Science,” STMIK Indones. Padang, vol. 6, no. 1, p. 62, 2018.

[3] R. M. Munthe and A. S. Rms, "Sistem Pendukung Keputusan Menentukan Karyawan Terbaik Dengan Metode AHP," vol. 3, no. 2, pp. 119-125, 2018.

[4] M. M. Ibrahim and W. Karis, "Pemilihan Karyawan Terbaik Menggunakan Metode Analytical Hierarchy Process ( Ahp ) Pada Pt . Virama Karya Cabang Semarang," Sist. Pendukung Keputusan Pemilihan Karyawan Terbaik Menggunakan Metod. Anal. Hierarchy Process Pada Pt. Virama Karya Cab. Semarang, vol. 1, no. 1, pp. 1-13, 2017.

[5] I. Wijaya, "Penerapan Metode AHP dan VIKOR Dalam Pemilihan Karyawan Berprestasi," pp. 301-309, 2019.

[6] S. H. Saragih, "Penerapan Metode Analitycal Hierarchy Process ( Ahp ) Pada Sistem Pendukung Keputusan Pemilihan Laptop,” Sylvia Hartati Saragih, pp. 82-88, 2013.

[7] S. Pekanbaru, "Aplikasi Sistem Pemberian Reward Berdasarkan Kinerja Karyawan Dengan Metode Analytical Hierarchy Process ( Ahp ) Pada Toko Golden Jaya,” vol. 2, no. 1, pp. 87-101, 2019.

[8] A. Sasongko, I. F. Astuti, and S. Maharani, "Pemilihan Karyawan Baru Dengan Metode AHP (Analytic Hierarchy Process)," Inform. Mulawarman J. Ilm. Ilmu Komput., vol. 12, no. 2, p. 88, 2017, doi: 10.30872/jim.v12i2.650.

[9] IR, "Sistem Pendukung Keputusan Pemberian Penerima Beasiswa Prestasi Peningkatan Akademik ( PPA ) Menerapkan Metode AHP dan WASPAS," pp. 418-425, 2019.

[10] I. Rijayana, L. Okirindho, F. Teknik, and U. Widyatama, "Sistem pendukung keputusan pemilihan karyawan berprestasi berdasarkan kinerja menggunakan metode analityc hierarcy process," vol. 2012, no. semnasIF, pp. 48-53, 2012. 